Vol. 8 (3): 585-590 (2018)

\title{
DIABETIC CARDIOMIOPATHY CLINICAL FEATURES
}

\author{
Eduard Spahiu $^{1 *}$, Klodiana Spahiu ${ }^{1}$ \\ ${ }^{I}$ Regional Hospital, Durres, Albania; \\ *Corresponding author Eduard Spahiu, email: edispahiu@ yahoo.com;
}

Received May, 2018; Accepted May, 2018; Published June, 2018;

DOI: https://doi.org/10.31407/ijees8319

UOI license: http://u-o-i.org/1.01/ijees/05529740

\begin{abstract}
Diabetes is associated with increased incidence of heart failure even after controlling for coronary artery disease and hypertension. Thus, as diabetic cardiomyopathy has become an increasingly recognized entity among clinicians, a better understanding of its pathophysiology is necessary for early diagnosis and the development of treatment strategies for diabetes-associated cardiovascular dysfunction. The pathogenesis of diabetic cardiomyopathy is partially understood and is likely to be multifactorial, involving metabolic disturbances, hypertension and cardiovascular autonomic neuropathy. Therefore, an important need remains to further delineate the basic mechanisms of diabetic cardiomyopathy and to apply them to daily clinical practice. This is a systematic review of recent basic and clinical research into the manifestations and the pathophysiological mechanisms of diabetic cardiomyopathy.
\end{abstract}

Keywords: diabetic cardiomyopathy, diabetes mellitus, left ventricular hypertrophy, left ventricular dysfunction. 